\title{
Exposure to infrasonic noise in agriculture
}

\author{
Bartosz Bilski ${ }^{1}$ \\ 1 University of Medical Sciences in Poznań 2. Dezydery Chłapowski Research Institute \\ Bliski B. Exposure to infrasonic noise in agriculture. Ann Agric Environ Med. 2017; 24(1): 86-89. doi: 10.5604/12321966.1233897
}

\begin{abstract}
Introduction and objectives. Although exposure to audible noise has been examined in many publications, the sources of infrasound in agriculture have not been fully examined and presented. The study presents the assessment of exposure to infrasound from many sources at workplaces in agriculture with examples of possible ergonomic and health consequences caused by such exposure.

Materials and method. Workers'-perceived infrasonic noise levels were examined for 118 examples of moving and stationary agricultural machines (modern and old cab-type tractors, old tractors without cabins, small tractors, grinders, chargers, forage mixers, grain cleaners, conveyors, bark sorters and combine-harvesters). Measurements of infrasound were taken with the use of class 1 instruments (digital sound analyzer DSA-50 digital and acoustic calibrator). Noise level measurements were performed in accordance with PN-Z-01338:2010, PN-EN ISO 9612:2011 and ISO 9612:2009.

Results and conclusions. The most intense sources of infrasound in the study were modern and old large size types agricultural machinery (tractors, chargers and combined-harvesters, and stationary forage mixers with ventilation). The G-weighted infrasound levels were significant and at many analyzed workplaces stayed within or exceeded the occupational exposure limit $\left(\mathrm{L}_{\mathrm{G} \mathrm{eq}, 8 \mathrm{~h}}=102 \mathrm{~dB}\right)$ when the duration of exposure is longer than $22 \mathrm{~min}$./8-hours working day (most noisy - modern cab-type tractors), 46 min./8 hours working day (most noisy - old type cab-tractors), 73 min./8 hours working day (most noisy - old tractors without cabins), 86 min./8-hours working day (most noisy - combine-harvesters) and $156 \mathrm{~min} . / 8$ hours working day (most noisy - stationary forage mixers with ventilation). All measured machines generated infrasonic noise exceeded the value $L_{G \text { eq, Te }}=86 \mathrm{~dB}$ (occupational exposure limit for workplaces requiring maintained mental concentration). A very important harmful factor is infrasound exposure for pregnant women and adolescents at workplaces in agriculture. Very valuable work can be technical limiting exposure to infrasound from new and used agricultural machinery. The technical limitation of infrasound caused by both old and new agricultural machinery can be invaluable from the work point of view.
\end{abstract}

Key words

infrasound, infrasonic noise, tractors, combined-harvesters, work hygiene, occupational exposure, agriculture

\section{INTRODUCTION}

Audible and infrasonic noise is a significant hazard in agriculture. Although exposure to audible noise has been examined in many publications thet sources of infrasound in agriculture have not been fully examined and presented [1, 2]. Infrasound consists of acoustic oscillations the frequency of which is below the low frequency limit of audible sound (16 Hz, more commonly considered as $20 \mathrm{~Hz}$ ) (IEC, 1994), but this definition is incorrect as sound remains audible at frequencies well below $16 \mathrm{~Hz}$ [3].

Individual farm owners and workers on large farms are exposed to multiple-sources of infrasonic noise (self-propelled farming machines, e.g. combines of various types, tractors in combination with farming machines, moving machines, chaff cutters, chargers, stationary farming machines, e.g. grain mills, threshing machines, crushers, grinders, mixers, milking machines and environmental sources of infrasound, e.g. wind turbines and natural sources of infrasound). The variability of audible and infrasonic noise exposure at the workplaces is very characteristic in agriculture, depending on the type of farm, seasonality of work, work organization, level of mechanization and weather conditions $[4,5,6]$.

The infrasound levels generated by many sources in agriculture vary considerably in individual sources, depending of various factors, including type of machine,

Address for corespodnence: Bartosz Bilski, University of Medical Sciences in Poznań 2. Dezydery Chłapowski Research Institute, Poland

E-mail: bilski@ump.edu.pl

Received: 7 August 2016; accepted: 8 November 2016; first published on January 2017 engine, power of the engine, engine loads, speeds, type of work, weather and soil conditions, operator's skills, distance from source, etc. Protection against infrasound is difficult because infrasound waves are weakly damped and easily spread over long distances from the source, and are subject to the phenomenon of resonance. Traditional methods of suppression in the case of infrasound are not very effective. There is no point in using personal hearing protection; therefore, combating infrasound has to be at the source. From practical point of view, the assessment of potential adverse health and mental effects of exposure to infrasound in agriculture can be very interesting, but such assessments can be very difficult because of the often co-exposure to audible noise, whole-body- and hand-arm-vibration $[4,5,6,7,8]$.

\section{OBJECTIVES}

The aim of the study was the assessment of exposure to infrasound from various sources at workplaces in agriculture, with examples of possible ergonomic and health consequences caused by such exposure.

\section{MATERIALS AND METHOD}

Workers'-perceived infrasonic noise levels were examined for 118 examples of moving and stationary agricultural machines (modern and old cab-type tractors, old tractors without cabins, small tractors, grinders, chargers, forage 
mixers, grain cleaners, conveyors, bark sorters and combineharvesters).

Measurements of infrasound were taken with the use of class 1 instruments by SONOPAN, a DSA-50 digital sound analyzer and a KA-50 acoustic calibrator. All measuring instruments had calibration certificates. The parameters set in the DSA-50 sound level meter were as follows: basic error up to $0.7 \mathrm{~dB}$, influence of temperature up to $0.5 \mathrm{~dB}$, influence of humidity up to $0.1 \mathrm{~dB}$, influence of atmospheric pressure $0.01 \mathrm{~dB} \mathrm{kPa}$, influence of electrostatic/electromagnetic fields, consistent with EN 61672-1 [9].

Noise level measurements were performed in accordance with PN-Z-01338:2010, PN-EN ISO 9612:2011 and ISO 9612:2009 [10, 11]. These standards determine the 5-step procedure for the analysis of occupational exposure to noise: 1) analysis of working conditions, 2) selection of measurements strategy, 3) analysis of uncertainty and errors 4) calculation and 5) presentation of the results, including the uncertainty of measurement. All measurements were taken using a G filter (the most popular filter for infrasound exposure analysis) and a LIN filter (e.g. in Polish conditions, this filter is used by legal requirement (Fig. 1) $[12,13,14]$. Frequency characteristics of the $G$ filter corresponds to subjective evaluation of infrasound nuisance. The measurement results included equal infrasound $\mathrm{G}$-weighted levels $\left(\mathrm{L}_{\mathrm{G} \text { eq,Te}}\right)$ - the basis of assessment of exposure to infrasonic noise measurements (PN-01338:2010) - and additionally, maximum acoustic pressure levels in the infrasonic band $\left(\mathrm{L}_{\text {LINmax }}\right.$ ) (required by some legal regulations concerning women and young workers) $[13,14,15]$. Measurement uncertainty was assessed according to Annex C of PN-EN ISO 9612:2011 (ISO 9612:2009) (recommended by paragraph 4.5. of PN-Z01338:2010), assuming that exposure to infrasound during a particular task was identical during an 8-hour working day to the exposure during the time of measurement (Te), which is $\mathrm{L}_{\text {Geqsh }}=\mathrm{L}_{\text {Geq,Te }}$. Measurements were performed on accordance with EN ISO/IEC 17025:2005 and in cooperation with a laboratory for noise accredited by Polish Centre for Accreditation, which is a signatory of the European Cooperation for Accreditation (EA MLA) and International Laboratory Accreditation Cooperation (ILAC MRA) [16].

\section{RESULTS AND DISSCUSSION}

The results of infrasonic noise measurements are shown in Table 1. The most important sources of infrasound were: tractors, chargers, combined-harvesters and stationary forage mixers with ventilation. This is a very important problem from the practical (technical, medical and ergonomic) point of view.

The following occupational exposure limits for infrasonic noise are obligatory in Poland, according to PN-Z-01338:2010 [11]:

1) maximum equivalent acoustic pressure level corrected by a specific $G$ frequency filter with reference to an 8-hour-long daily exposure, total working time, or a typical working week (if the exposure varies on specific week-days: $\mathrm{L}_{\mathrm{Geq}, 8 \mathrm{~h}}$ or $\left.\mathrm{L}_{\text {Geq,week }}\right)=102 \mathrm{~dB}$;

2) the $G$-weighted maximum equivalent acoustic pressure level $\left(\mathrm{L}_{\mathrm{G} \text { eq,Te}}\right)=86 \mathrm{~dB}$ at workplaces where the workers are required to maintain a high level of concentration.

These values were determined based on the criteria for health (especially hearing protection). However, they do not correspond to the threshold of auditory perception infrasound, which is related to frequency characteristics $\mathrm{G}$, which correlates well with the subjective assessment of the nuisance value and perception of infrasound. The accompanying whole-body vibration can result especially in damage to the vestibule-cochlear organ. The high concentration of a worker is needed at many workplaces, as presented in this study, and is connected with opportunities for accidents. Similarly, there are special restrictions concerning infrasound exposure which apply to pregnant women and young workers. For example, in Poland, for pregnant women and young workers the limits for an 8-hour working day or work week, the values $\left(\mathrm{L}_{\mathrm{Geq}, 8 \mathrm{~h}}\right.$ or $\left.\mathrm{L}_{\mathrm{Geq}, w e e k}\right)$ are following: $86 \mathrm{~dB}$ and $\mathrm{L}_{\mathrm{LIN}} 135 \mathrm{~dB}$ are applied [13, 14]. The early Polish law regulation required additionally the value $145 \mathrm{~dB}$ as the level of maximum acoustic pressure $\left(\mathrm{L}_{\mathrm{LIN}}\right)$ [15].

Unfortunately, in the presented study, the G-weighted infrasound levels were significant and at many workplaces stayed within or exceeded the occupational exposure limits

Table 1. Results of infrasound measurements among various sources in agriculture

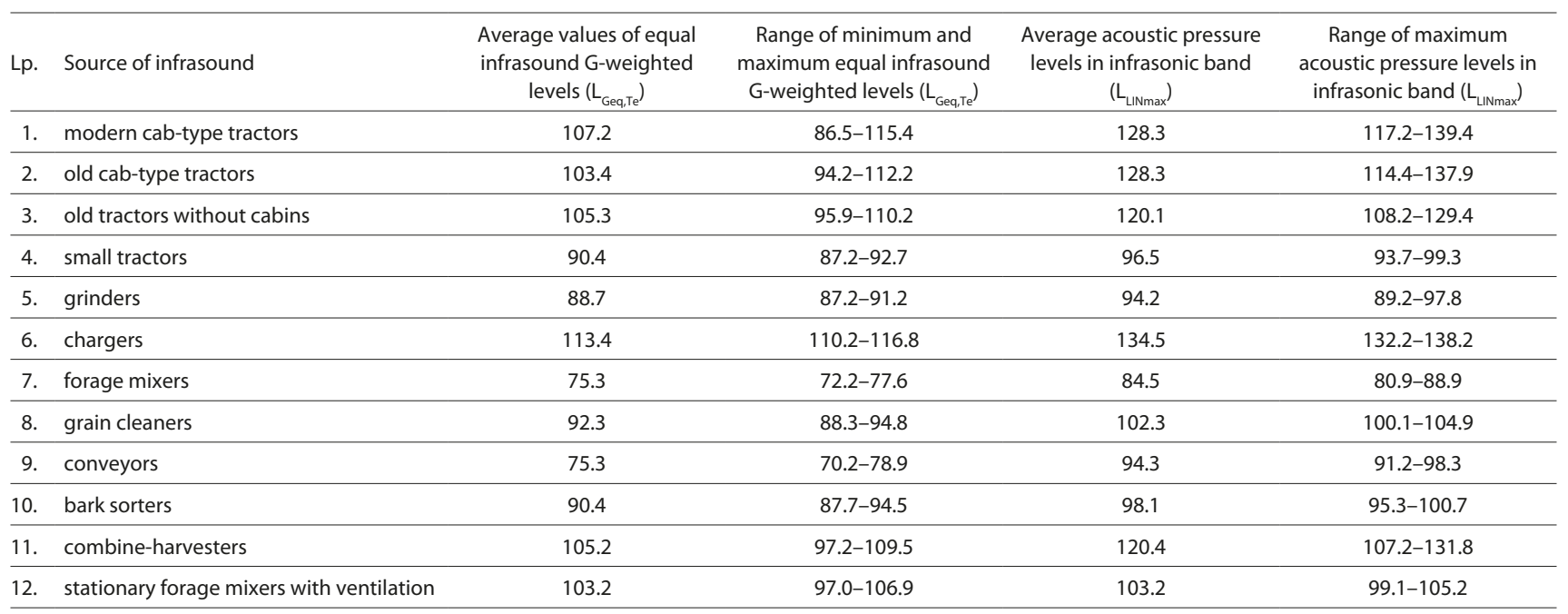

Expanded uncertainty of equal infrasound $\mathrm{G}$-weighted levels $\left(\mathrm{L}_{\mathrm{Geq}}\right)$ from each analyzed source up to $+2.6 \mathrm{~dB}$ (assuming an $8 \mathrm{~h}$-duration of exposure). Uncertainty of maximum acoustic pressure levels in infrasonic band (L $\left.\mathrm{L}_{\text {UNmax }}\right)$ up to $+2.0 \mathrm{~dB}$ 
$\left(\mathrm{L}_{\mathrm{Geq} 8 \mathrm{~h}}=102 \mathrm{~dB}-\mathrm{G}\right)$ when the duration of exposure lasted longer than $22 \mathrm{~min}$. (most noisy - modern cab-type tractors), 46 min. (most noisy - old type cab-tractors), 73 min. (most noisy - old tractors without cabins), $86 \mathrm{~min}$. (most noisy combine-harvesters) and $156 \mathrm{~min}$. (most noisy - stationary forage mixers with ventilation). All measured machines generated infrasonic noise exceeded the value $\mathrm{L}_{\mathrm{Geq}, \mathrm{Te}}=$ $86 \mathrm{~dB}$ (workplaces which required maintaining mental concentration, according to PN-Z-01338:2010), and for pregnant women and young workers (when the duration of exposure is at the 8-hour level $\left(\mathrm{L}_{\mathrm{G} \text { eq,Te }}=\mathrm{L}_{\mathrm{Geq}, 8 \mathrm{~h}}\right)$.

Infrasound can cause adverse effects on the vestibulocochlear organ (audible effects and influence on body equilibrium) and generate audible and various non-audible effects, for example [17], psychological and mental reactions. Some studies have indicated that prolonged exposure to infrasonic noise at levels of about $90 \mathrm{~dB}-\mathrm{G}$ may cause a lot of psychological and mental reactions: headaches, drowsiness, excessive fatigue, sluggishness, slowing of reaction time, decrease of psychomotor efficiency, irritation, hearing loss, and increase in psychological tension. Infrasonic noise levels within the range of sound levels of 90-120 dBG may cause symptoms of strain characteristic of a lowered state the alertness of the central nervous system. Operators or drivers can have disrupted attention, disrupted perception of surrounding activities, and diminished sharpness and field of vision. The researches indicated that the reaction time in psychomotor efficiency tests becomes extended by $30-40 \%$ at infrasound levels of $115-120 \mathrm{~dB}$. Vehicle drivers exposed to simulated infrasound at levels of 100-135 dB for 15 minutes reported feelings of fatigue, apathy, depression, vibrations of internal organs, loss of concentration, and pressure in the ears [18-25].

It must be borne in mind that similar studies in the human population have revealed many distressing adverse results of experimental research involving high exposures of infrasound, for example:

- adverse influence on the respiratory and cardiovascular systems, metabolism of myocytes, endothelium of vessels, blood pressure and blood coagulation [26-32];

- adverse influence on the respiratory tissue [33];

- adverse influence on sexual behaviour [34];

- adversely affect the functions of neurons in different parts of the central and autonomic nervous systems, limbicreticular complex, hypothalamus, and other subcortical structures. These adverse influences can also cause diencephalic hypothalamic syndrome with sensor-somatic and autonomic visceral symptoms [35-40].

- adverse influence on the functions of the gastrointestinal organs, spleen and liver $[41,42,43]$,

- cause visual impairment [44];

- affects hormonal equilibrium [34, 45].

The general limits of adverse effects thresholds are presented in Figure 2 [46].

A significant problem is the coincidence of vibration and infrasonic noise at many of the analyzed workplaces. For example, the highest levels of whole-body vibration in the seat of agricultural tractors remain mainly within the range of frequencies of $1-10 \mathrm{~Hz}$, equivalent to the resonance frequencies for many human body organs. Infrasonic noise can also induce resonance vibrations in the chest, diaphragm, and digestive tract and organs. An important factor that can

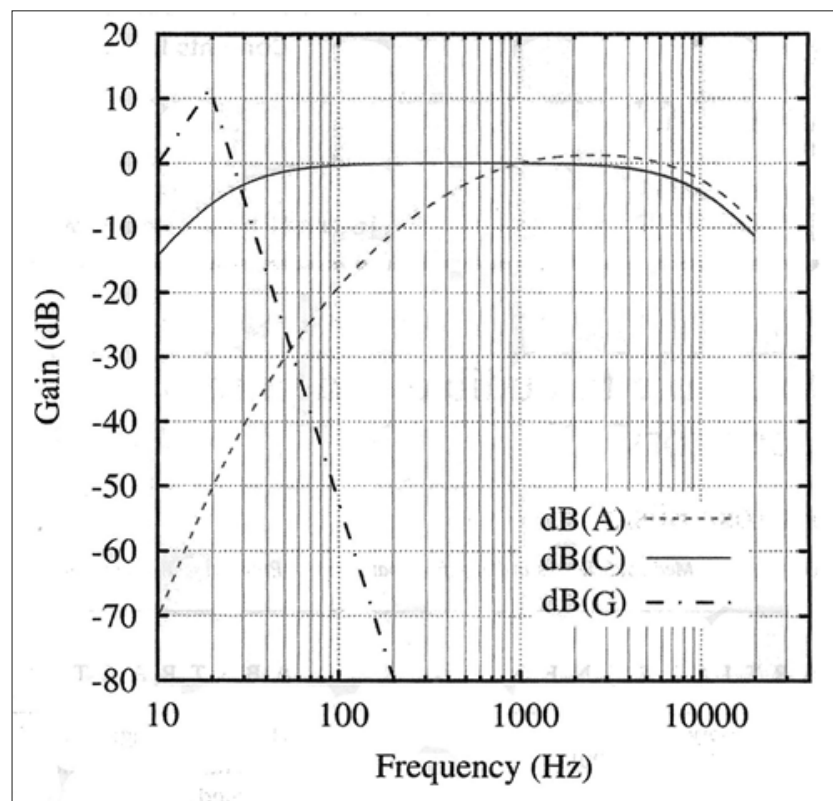

Figure 1. Frequency characteristics of $G$ and LIN filters applied in infrasonic noise measurement applied in working environments [11, 12, 13, 14, 15]

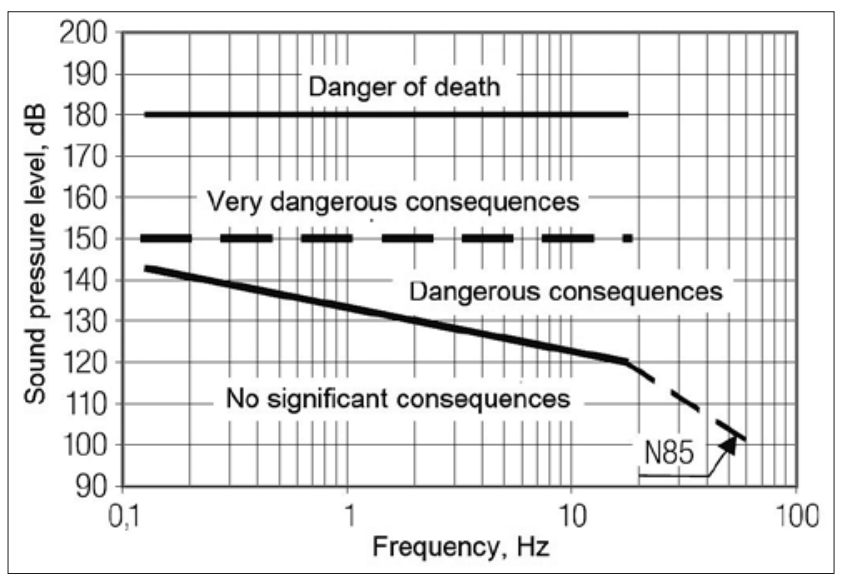

Figure 2. Threshold levels of human health infrasound effects proposed by M. Stan during the Colloquium on Infrasound in Paris in 1973 [46]

influence infrasound levels inside vehicles or cabins is the position of windows which, depending on their position and the resonance frequency, can amplify the infrasound and vibration levels.

\section{CONCLUSIONS}

1. The most intense sources of infrasound were both old and modern, large size agricultural machinery: tractors, chargers and combine-harvesters, and stationary forage mixers with ventilation.

2. The G-weighted infrasound levels were significant and at many analyzed workplaces stayed within or exceeded the occupational exposure limit $\left(\mathrm{L}_{\mathrm{G} \mathrm{eq}, 8 \mathrm{~h}}=102 \mathrm{~dB}-\mathrm{G}\right)$ when the duration of exposure was longer than $22 \mathrm{~min}$. (most noisy - modern cab-type tractors), 46 min. (most noisy old type cab-tractors), $73 \mathrm{~min}$. (most noisy - old tractors without cabins), $86 \mathrm{~min}$. (most noisy - combine-harvesters) and $156 \mathrm{~min}$. (most noisy - stationary forage mixers with ventilation). 
3. All measured machines generated infrasonic noise which exceeded the value $\mathrm{L}_{\mathrm{G} \text { eq,Te}}=86 \mathrm{~dB}$ (occupational exposure limit for workplaces which required maintaining mental concentration).

4. A very important harmful factor was infrasound exposure for pregnant women and adolescents at the analyzed workplaces in agriculture.

5. Very valuable work can be technical limiting exposure to infrasound from new and used agricultural machinery. The technical limitation of infrasound caused by old and new agricultural machinery can be invaluable from the work point of view.

\section{REFERENCES}

1. Bilski B. Exposure to audible and infrasonic noise by modern agricultural tractors operators. Applied Ergonomics. 2013; 44: 210-214.

2. Bilski B. Audible and infrasonic noise levels in the cabins of modern agricultural tractors- does the risk of adverse, exposure-dependent effects still exist? Int J Occup Med Environ Health. 2013; 26(3): 488-493.

3. IEC 1994. 60050-801:1994 International electrotechnical vocabularychapter 801: acoustics and electroacoustics.

4. Solecki L. Evaluation of annual exposure to noise among private farmers on selected family farms of animal production profile. Ann Agric Environ Med. 2005; 12: 67-73.

5. Solecki L. Characteristics of private farmers' noise exposition fluctuations levels- methodical proposals. Bezp Pr. 2002; 9: 19-21.

6. Solecki L. Duration of exposure to noise among farmers as an important factor of occupational risk. Ann Agric Environ Med. 2000; 7: 89-93.

7. Solecki L. Preliminary recognition of whole body vibration risk in private farmers' working conditions. Ann Agric Env Med. 2007; 14: 299-304.

8. Solecki L. Assessment of annual exposure of private farmers to whole body mechanical vibration on selected family farms of plant production profile. Ann Agric Env Med. 2010; 17: 243-250.

9. ISO $61672: 2003$. Electroacoustic- sound level meters. International Ogranization for Standardization.

10. EN ISO 9612:2009. Acoustics- determination of occupational noise exposure- engineering method.

11. PN-Z-01338:2010 Acoustics- measurement and assessment of infrasonic noise at the workplaces. PKN Warsaw 2010).

12. ISO 7196:1995 Acoustics- frequency weighting characteristic for infrasound measurements. International Organization for Standardization.

13. Polish Council of Ministers of 29 August 2016: The list of works forbidden to the juvenile and the conditions of employing them at some of these jobs.

14. Regulation of Polish Minister of Labour and Social Policies of 29 November 2002 on high admissible exposures and concentrations levels in work environment. Off. J. Poland (217), 2002, position 1833.

15. Polish Council of Ministers of 30 July 2002. The list of works forbidden to women.

16. ISO/IEC 17025:2005. General requirements for the competence of testing and calibration laboratories.

17. Hensel J, Scholz G, Hurttig U, Mrowinski D, Janssen T. Impact of infrasound on the human cochlea. Hear Res. 2007; 233; (1-2): 67-76.

18. Benton S. Experiments into the effects of low frequency noise upon human behavior; a pitot study. In: Proc of Internoise: 891-894.

19. Landström U, Lundström R, Byström M: Exposure of infrasound perception and changes in wakefulness. J Low Freq Noise Vibr. 1983; 2: $1-11$.

20. Landström U, Lindblom-Häggqvist S, Löfstedt P. Low frequency noise in lorries and correlated effects on drivers. J. Low Freq Noise Vibr. 1988; 7: 104-109.

21. Nowacki G., Mitraszewska I., Kamiński T., Wierzejski A.: Research of infrasound noise in heavy goods vehicle and busses. In the: $8^{\text {th }}$ International Conference Reliability and Statistics in Transportation and Communication, 15-18 October 2008.
22. Sandberg U. Combined effects of noise, infrasound and vibration on driver performance. In: Proc. of Internoise, 1983; 887-890.

23. Sandberg U. Identification of infrasound generation mechanisms in a bus. In: Proceedings of the $4^{\text {th }}$ International Meeting on Low Frequency Noise and Vibration. Umel University. Umel Sweden.

24. Fairley TE. Predicting the discomfort caused by tractor vibration. Ergonomics. 1995; 38: 2091-2106.

25. Futatsuka M, Maeda S, Inaoka T, Nagano M, Shono M, Miyakita T. Whole body vibration and health effects in the agricultural machinery drivers. Ind Health. 1998; 36: 127-132.

26. Pei Z, Zhuang Z, Xiao P, Chen J, Sang H, Ren J, Wu Z, Yan G. Influence of infrasound exposure on the whole L-type calcium currents in rat ventricular myocytes. Cardiovasc Toxicol. 2009; 9(2): 70-7.

27. Gordeladze AS, Glinchikov VV, Usenko VR. Experimental myocardial ischemia caused by infrasound. Gig Tr Prof Zabol. 1986; (6): 30-3.

28. Nekhoroshev AS, Glinchikov VV. Morpho-functional changes in the myocardium after exposure to infrasound. Gig Sanit. 1991; 12: 56-8.

29. Pei ZH, Chen JZ, Zhu MZ. The changes of ultrastructure of rat vascular endothelia after infrasound exposure. Zhongguo Ying Yong Sheng Li Xue Za Zhi. 2005; 21(1): 39-40.

30. Chzhao Cg, Chén’ Tt, Chzhan Li. Influence of infrasound on angiotensin II content of rat serum. Med Tr Prom Ekol. 2004; (7): 21-24.

31. Pei Z, Sang H, Li R, Xiao P, He J, Zhuang Z, Zhu M, Chen J, Ma H. Infrasound-induced hemodynamics, ultrastructure, and molecular changes in the rat myocardium. Environ Toxicol. 2007; 22(2): 169-175.

32. Ma WM, Qi P, Zhang JZ, Yi Y, Chen XM, Zhang J, Han RG. The effects of infrasound on the blood coagulation function of guinea pigs. Zhonghua Lao Dong Wei Sheng Zhi Ye Bing Za Zhi. 2011; 29(3): 209-211.

33. Svidovy V, Glinchikov VV. Effect of infrasound on pulmonary structure. Gig Tr Prof Zabol. 1987; (1): 34-37.

34. Zhuang Z, Pei Z, Chen J. Infrasound-induced changes on sexual behavior in male rats and some underlying mechanisms. Environ Toxicol Pharmacol. 2007; 23(1): 111-114.

35. Arabadzhi V. Infrasound and biorhythms of the human brain. Biofizika. 1992; 37(1): 150-151.

36. Morioka I, Kuriyama Y, Miyashita K, Takeda S. Effects of infrasound on gastric mucosal blood flow in rats. Environ Health Prev Med. 1996; 1(2): 71-75.

37. Izmerov NF, Suvorov GA, Kuralesin NA, Ovakimov VG. Infrasound: body's effects and hygienic regulation. Vestn Ross Akad Med Nauk. 1997; 7: 39-46.

38. Liu J, Lin T, Yan X, Jiang W, Shi M, Ye R, Rao Z, Zhao G. Effects of infrasound on cell proliferation in the dentate gyrus of adult rats. Neuroreport. 2010 Jun 2;21(8):585-9.

39. Liu ZH, Chen JZ, Ye L, Liu J, Qiu JY, Xu J, Lu R, Yuan XC, Zhang WD, Li XF, Li G. Effects of infrasound at $8 \mathrm{~Hz} 90 \mathrm{~dB} / 130 \mathrm{~dB}$ on NMDAR1 expression and changes in intracellular calcium ion concentration in the hippocampus of rats. Mol Med Rep. 2010; 3(6): 917-921.

40. Cheng H, Wang B, Tang C, Feng G, Zhang C, Li L, Lin T, Du F, Duan $\mathrm{H}$, Shi M, Zhao G. Infrasonic noise induces axonal degeneration of cultured neurons via a $\mathrm{Ca}^{2+}$ influx pathway. Toxicol Lett. 2012; 212(2):190-197.

41. Morioka I, Kuriyama Y, Miyashita K, Takeda S. Effects of infrasound on gastric mucosal blood flow in rats. Environ Health Prev Med. 1996; 1(2): 71-75.

42. Nekhoroshev AS, Glinchikov VV. Morphological research on the liver structures of experimental animals under the action of infrasound. Aviakosm Ekolog Med. 1992; 26(3): 56-59.

43. Chen YM, Ye L, Gao SB, Zhu DH, Luo WJ, Liu XH, Chen JY, Chen JZ. Effects of infrasound exposure on several enzymes activities of spleen and liver in rats. Zhongguo Ying Yong Sheng Li Xue Za Zhi. 2004; 20(2): 176-179.

44. Qiu P, Zhang Z, Jiang Y, Gou Q, Wang B, Gou L, Chen J. Effect of infrasound on ultrastructure and permeability of rat's blood-retinal barrier. Zhonghua Yan Ke Za Zhi. 2002; 38(8): 499-501.

45. Dang WM, Wang S, Tian SX, Chen B, Sun F, Li W, Jiao Y, He LH. Effects of infrasound on activities of 3 beta hydroxysteroid dehydrogenase and acid phosphatase of polygonal cells in adrenal cortex zona fasciculate in mice. Zhonghua Lao Dong Wei Sheng Zhi Ye Bing Za Zhi. 2007; 25(2): 91-95.

46. Broner N. The effects of low frequency noise on people. J Sound Vib. $1978 ; 58: 483-500$. 